http://www.rasi.uff.br

RASI, Volta Redonda/RJ, v. 5, n. 2, pp. 241-265, mai./ago. 2019

\title{
Massive Open Online Courses na oferta de ensino de Empreendedorismo e Sustentabilidade
}

\author{
Alexandre Adriano dos Santos Lima (IFRS) - alexandre.lima@restinga.ifrs.edu.br \\ André Luís Furtado da Hora (UFF) - andrefhora@gmail.com \\ Douglas Kellermann (IFRS) - douglaskellermann@gmail.com \\ Jéssica Souza Maia (UFF) - jessicamaia@id.uff.br \\ Thalyta Sá de Carvalho (UFF) - thalytascarvalho@gmail.com
}

\begin{abstract}
RESUMO
O empreendedorismo contemporâneo é uma das molas propulsoras do desenvolvimento econômico, que deve contemplar o aspecto social, alinhado com os princípios de sustentabilidade. Instituições de ensino podem utilizar as tecnologias educacionais para inovar no fomento às iniciativas de empreendimentos sustentáveis. O presente artigo tem por objetivo realizar uma análise em cursos ofertados em plataformas Massive Open Online Course (MOOC) que relacionem os temas empreendedorismo e sustentabilidade. Esta proposta surgiu a partir de experiência em curso intensivo sobre estes temas, contextualizados em problemas reais, mobilizando os estudantes para conhecer e empreender soluções inovadoras e sustentáveis para diferentes desafios. Buscando observar tal experiência em cursos online, procurou-se desenvolver um estudo de casos múltiplos analisando as práticas na oferta MOOC segundo parâmetros e referências para educação do empreendedorismo orientado à sustentabilidade. Acredita-se que a oferta de MOOC, pode contribuir na disseminação de habilidades empreendedoras e atitudes sustentáveis. Para tanto, devem ser observados requisitos qualificatórios do processo de ensino e aprendizagem e metodologias ativas de ensino que abordem problemas concretos, articulando empreendedorismo e sustentabilidade. Constatou-se que o formato MOOC mostra-se como importante canal para a Universidade contribuir socialmente no compartilhamento de práticas de inovação empreendedora sustentável, inovando também em sua missão de educar ao explorar novas tecnologias educativas.
\end{abstract}

Palavras-Chave: Educação; Empreendedorismo; MOOC; Sustentabilidade.

Massive Open Online Courses Offering Education in Entrepreneurship and Sustainability

\begin{abstract}
Contemporary entrepreneurship is one of the propulsive springs of economic development, which must contemplate the social aspect, aligned with the principles of sustainability. Educational institutions can use educational technologies to innovate in fostering sustainable enterprise initiatives. The purpose of this article is to analyze courses offered on Massive Open Online Course (MOOC) that relate the themes of entrepreneurship and sustainability. This proposal emerged from intensive experience on these themes, contextualized in real problems, mobilizing the students to know and to develop innovative and sustainable solutions for different challenges. Seeking to observe such experience in online courses, we tried to develop a multiple case study analyzing the practices in the MOOC offer according to parameters and references for entrepreneurship education oriented towards sustainability. It is believed that the MOOC offer can contribute to the dissemination of entrepreneurial skills and sustainable attitudes. Therefore, qualifying requirements of the teaching and learning process and active teaching methodologies that address concrete problems, articulating entrepreneurship and sustainability must be observed. It was verified that the MOOC format shows itself as an important channel for the University to contribute socially in the sharing of practices of sustainable entrepreneurial innovation, also innovating in its mission to educate when exploring new educational technologies
\end{abstract}

Keywords: Education; Entrepreneurship; MOOC; Sustainability.

\section{은 Universidade \\ U1 Fluminense}

R. Desembargador Ellis Hermydio Figueira, 783, Bloco A, sl. 218, Aterrado.

27213-415 - Volta Redonda, RJ - Brasil

www.uff.br

Copyright (C) 2019 RASI. Todos os direitos, até mesmo de tradução, são reservados. É permitido citar parte de artigos sem autorização prévia, desde que seja identificada a fonte. 


\section{Massive Open Online Courses na Oferta de Ensino de Empreendedorismo e Sustentabilidade}

\section{Introdução}

Desafios originados das mudanças rápidas na dinâmica global dos sistemas econômicos e políticos exigem ação conjunta de governos, universidades, empresas e sociedade. Neste contexto, é necessário articular a cooperação multidisciplinar para o tratamento adequado das questões econômicas e sociais. O empreendedorismo sustentável é uma das bases para promoção de oportunidades de trabalho e renda, desenvolvimento econômico e social e deve nortear as ações de empreendimentos que buscam posicionar-se como inovadores na atualidade. Empreender requer atenção à três pilares (Elkington, 1994): sustentabilidade econômica, sustentabilidade ambiental e sustentabilidade social. Modelos de inovação como a Triple Helix buscam, através do envolvimento articulado de Universidade, Mercado e Governo, contribuir para o desenvolvimento social e econômico em diferentes regiões do globo (Etzkowitz \& Leydesdorff, 1997) estimulando, entre outras iniciativas, ações de empreendedorismo e sustentabilidade.

Um caminho que pode trazer resultados positivos de curto e médio prazo no enfrentamento de problemas concretos da sociedade é a universalização de conhecimento pela adoção de Massive Open Online Courses (MOOC). Tal formato de cursos abertos mostra-se como alternativa direcionada, modularizada e flexível que favorece diferentes possibilidades formativas. Pode-se explorar diferentes plataformas MOOC existentes compartilhando conhecimento e inovação para diferentes problemas econômicos e sociais. $\mathrm{O}$ desenvolvimento sustentável global, foco de pesquisas e publicações da Organização das Nações Unidas (ONU), tem na educação de qualidade um dos caminhos para reduzir a pobreza, promover a prosperidade e o bem-estar para todos, proteger o meio ambiente e enfrentar as mudanças climáticas.

Neste cenário, uma apropriada concepção de ensino de empreendedorismo orientada a sustentabilidade se torna de suma importância, assim como, selecionar as estratégias para universalizar e flexibilizar a aprendizagem destas temáticas.

Em meio à segunda revolução acadêmica, que coloca as instituições de ensino e pesquisa como protagonistas da missão de inovar (Etzkowitz \& Zhou, 2017), é oportuno valerse dos constantes avanços das tecnologias de informação e comunicação (TIC) para inovar também em todas as dimensões do tripé que compõe a missão da Universidade: ensino, pesquisa e extensão. Assim, há muito espaço em explorar as plataformas MOOC para compartilhamento dos mais novos conhecimentos sobre empreendedorismo e inovação. Neste contexto, surge a indagação: diante do crescimento da busca de conhecimento em plataformas MOOC, a oferta atual de cursos online abrangendo os temas empreendedorismos e sustentabilidade se mostra alinhada com o ensino demandado nesta área?

Com o objetivo de explorar a atual oferta destes cursos nas maiores plataformas MOOC, buscou-se: (1) identificar cursos existentes nas principais plataformas; (2) consultar a descrição do conteúdo dos cursos e outras informações disponíveis para conhecer a organização dos mesmos e temas contemplados; (3) analisar os conteúdos dos cursos para saber quais tratam sobre empreendedorismo e/ou sustentabilidade e qual a articulação desses temas nos conteúdos; (4) desenvolver considerações sobre o formato de oferta, práticas pedagógicas, avaliação dos 
estudantes, quando disponíveis tais informações, visando estabelecer um panorama da situação de oferta de cursos online nesta área.

\section{Revisão da Literatura}

A compreensão adequada do enfoque desta investigação requer uma apropriada conceituação de empreendedorismo e sustentabilidade no estrito sentido do que interessa à articulação desses temas, onde o primeiro é guiado pelo segundo. Complementa o embasamento necessário, apresentar pontos elementares sobre os MOOC como alternativa tecnológica e pedagógica para ensino e aprendizagem online.

\subsection{Empreendedorismo}

Talvez o maior obstáculo na discussão envolvendo empreendedorismo tem sido a sua definição. Inclusive na atualidade, a maioria dos pesquisadores definiram o campo apenas em termos de quem é o empreendedor e o que ele ou ela faz. O problema com esta abordagem é que o empreendedorismo envolve a combinação de dois fenômenos: a presença de oportunidades lucrativas e a presença de indivíduos empreendedores uma vez que, embora exista uma oportunidade, um indivíduo somente pode obter lucro se ele reconhecer que a oportunidade existe e tem valor (Venkataraman, 1997).

De acordo com Dolabella (2003), empreender é um processo humano, com toda a carga que isso representa: ações dominadas por emoção, desejos, sonhos, valores, ousadia de enfrentar as incertezas e de construir a partir da ambiguidade e no indefinido; consciência da inevitabilidade do erro em caminhos não percorridos; rebeldia e inconformismo; crença na capacidade de mudar o mundo; indignação diante de iniquidades sociais. Empreender é, principalmente, um processo de construção do futuro. O espírito empreendedor não é somente a coragem ou disposição para implantar um negócio, está intimamente ligado à inovação á serviço do crescimento, à exploração de um nicho de mercado imperceptível para muitos. É esse ciclo renovável que alimenta as possibilidades de expansão da economia. Esse conjunto é que motiva o empresário empreendedor para a plena liberdade de ação culminando, frequentemente, com a "destruição criativa" (Santiago, 2009).

No contexto de debates sobre se o empreendedorismo pode ser aprendido, há um crescente interesse global em educação e treinamento, conforme documentado pelo crescimento das ofertas de cursos em instituições educacionais (Kuratko, 2005) e por sua inclusão nas agendas internacionais e programas, como a Agenda de Oslo da Comissão Europeia e o Global Entrepreneurship Monitor.

Essa popularização da educação e treinamento em empreendedorismo é, em parte, impulsionada pelos interesses mútuos dos principais interessados, incluindo formuladores de políticas (o imperativo político para a criação de empregos), estudantes (mais graduandos competindo por menos empregos, buscando novas oportunidades e maneiras de diferenciação) e instituições de ensino (para satisfazer os formuladores de políticas, bem como o mercado estudantil por meio de ofertas de cursos) (Mwasalwiba, 2010). Tomados em conjunto, como indicativos de que os aspectos do empreendedorismo podem ser ensinados e aprendidos, os sistemas de educação e formação estão a emergir como um componente chave de discussões mais amplas sobre a promoção do empreendedorismo (Valerio, Parton \& Robb, 2014). 
Segundo relatório da European Commission (2009), a educação para o empreendedorismo define-se como a capacidade dos alunos desenvolverem as suas competências e mentalidades, tornando-se aptos à transformar ideias criativas em ação empreendedora. Trata-se de uma competência chave para todos os alunos, na medida em que apoia o desenvolvimento pessoal, a cidadania ativa, a inclusão social e a empregabilidade.

Francisco e Mariano (2017) destacam, ainda, que o ensino do empreendedorismo é reconhecido com um dos pilares da educação definidos pela Organização das Nações Unidas para a Educação, a Ciência e a Cultura (UNESCO). Além de "Aprender a Conhecer", "Aprender a Fazer", "Aprender a viver com os outros" e "Aprender a ser", no Projeto Regional de Educação para a América Latina e o Caribe, em 1998, foi estabelecido o pilar, "Aprender a Empreender"(Unesco, 1999).

\subsection{Sustentabilidade}

A questão da sustentabilidade vem sendo discutida há tempos. O termo é composto por uma série de atores que a ele despendem atenção e esforços, configurando um movimento de suma relevância para o século XXI (Barbieri, Vasconcelos, Andreassi \& Vasconcelos, 2010). A agenda deste movimento influencia os interesses de organizações públicas e privadas, da sociedade civil, impactando a gestão das empresas, levando à uma consciência no âmbito organizacional, para a assunção de políticas e práticas mais sustentáveis (Nidumolu, Prahalad \& Rangaswashi, 2009).

O conceito de sustentabilidade em questão, implica na ideia de que uma construção coesa e equilibrada de limites à exploração dos recursos ambientais é necessária, com a presença dos diversos atores da sociedade na construção destes limites, com a presença de diálogo, permeado por ética e corresponsabilidade (Jacobi, 2003).

Nas reflexões a respeito das origens e desenvolvimento do termo sustentabilidade, Yamamoto (2016) afirma que desenvolvimento sustentável abarca três dimensões: social, econômica e ambiental. Este tripé compõem o denominado Triple Bottom Line, abordagem desenvolvida inicialmente por Elkington, em 1994, com o entendimento em três P's: people, profit e planet (pessoas, lucro e planeta). Posteriormente, Carter e Rogers (2008) ratificaram a visão, construindo o modelo da Triple Bottom Line. Estes autores afirmam que tal visão institui uma relação transparente, propiciando a consecução de objetivos sociais, ambientais e econômicos, fomentando as organizações a elevarem seus padrões de competitividade a longo prazo (Carter \& Rogers, 2008; Yamamoto, 2016). 


\section{Figura 1. Representação Modelo Triple Bottom Line}

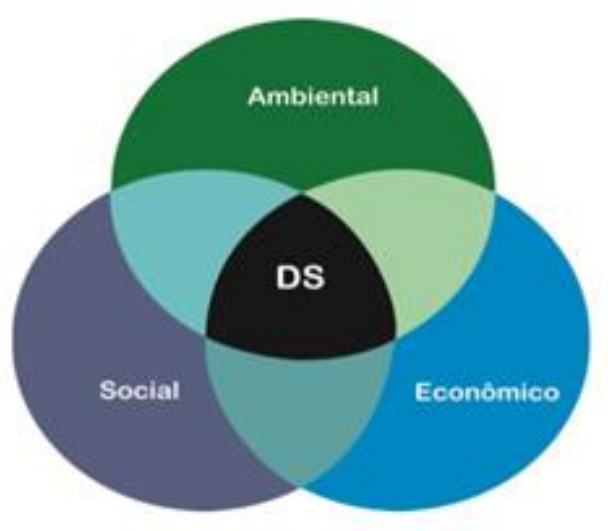

Fonte: Carter e Rogers, 2008

\subsection{Ensino e aprendizagem de empreendedorismo e sustentabilidade}

O aumento da escala de produção e do consumo (onde os recursos naturais são explorados, elevando a quantidade de resíduos gerados) foi um dos principais fatores que levou ao aumento crescente de problemas ambientais (Barbieri, 2007). Mas foi a partir da Revolução Industrial e, mais tarde, com o surgimento do fordismo e dos padrões massificados de produção e de consumo que os mesmos proporcionavam, que os problemas ambientais se intensificaram, tornando-se cada vez mais visíveis para a sociedade. Deste ponto, então, começam a surgir em todo o mundo uma série de eventos que contribuíram para a tomada de consciência do problema ambiental (Dias, 2006; Barbieri, 2007).

Blewitt e Cullingford (2004), argumentam que na Eco-92, Conferência das Nações Unidas sobre o Meio Ambiente e Desenvolvimento, realizada no Rio de Janeiro, a educação foi identificada como uma das forças centrais para os processos de desenvolvimento sustentável durante o século XXI. Alguns anos mais tarde, engajar-se seriamente com a meta da sustentabilidade e a necessidade de educação, em todas as suas formas, permanece mais significativo do que nunca.

Em geral, muito é visto, aplicado e estudado sobre empreendedorismo. Diversos são os autores e estudiosos da área. Em contrapartida, a sustentabilidade também é uma temática de interesse crescente na academia. A partir da seleção por métodos bibliométricos de publicações científicas sobre relatos de experiências educacionais destes dois temas, os autores Hermann e Bossle (2018) propuseram a conceituação de educação de empreendedorismo orientado a sustentabilidade.

Pesquisas anteriores relatam exaustivamente a integração de elementos de sustentabilidade dentro da educação para o empreendedorismo (Lourenço et al. 2013). A ideia é que a educação empresarial é o domínio pedagógico predominante e, em seguida, elementos de sustentabilidade devem ser adicionados com o objetivo de propor novas lentes que facilitem a identificação sustentável de oportunidades (Wyness \& Klapper, 2015).

Os aspectos positivos da educação voltada para a sustentabilidade podem ser integrados juntamente com outras competências e desenvolvimento de habilidades características da educação para o empreendedorismo, o que tornaria possível resolver algumas das armadilhas comuns, até então ligadas à integração da sustentabilidade no ensino de negócios, como a falta 
de motivação de professores, ou a aparente obrigação em incorporar a sustentabilidade no currículo sem uma verdadeira unidade de instrutores para tal finalidade (Jose, 2016).

Com base na análise de frequências em que certos conceitos são utilizados na literatura, os autores Hermann e Bossle (2018) chegaram a proposta de "educação empreendedora orientada para sustentabilidade", a qual dependeria de: i) foco educacional ii) abordagens de aprendizagem e de ensino apropriadas, iii) temas relacionados com empreendedorismo e sustentabilidade com articulação apropriada e iv) colaboração externa de diferentes atores, conforme mostrado na Figura 2:

Figura 2. Conceituando "Empreendedorismo orientado à educação sobre sustentabilidade"

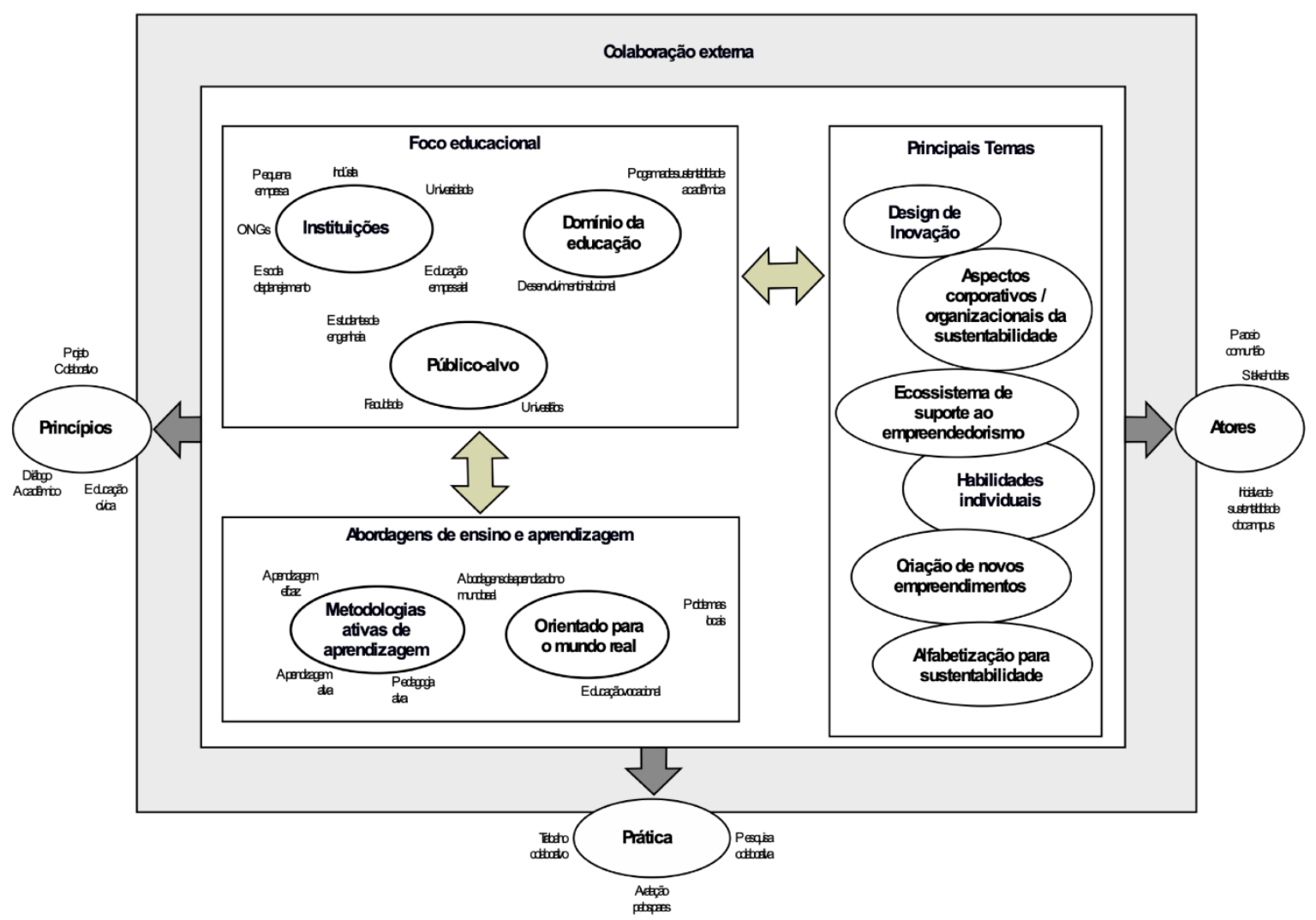

Fonte: Hermann e Bossle (2018, traduzido do original).

Para alcançar este modelo, o primeiro passo torna-se o enfrentamento de críticas às abordagens pedagógicas, onde a sustentabilidade é apenas percebida como "algo a mais" que é inserida em cursos já existentes, focados em outros aspectos do desenvolvimento de negócios (Wyness \& Klapper, 2015; Jose, 2016). Como um segundo aspecto, o quadro elaborado expande o papel da sustentabilidade, integrando-o com a educação de negócios / empreendedorismo, e não só sugerindo seu potencial para facilitar a identificação de oportunidades sustentáveis / verdes, mas também abordando o "como" uma combinação entre sustentabilidade e educação pode ser aplicada para o empreendedorismo, visando orientar de forma sistêmica o coletivo, com foco multidisciplinar.

Tal modelo se constitui de referência singular para observação da oferta de cursos online nesta área. 


\subsection{Massive Open Online Courses - MOOC}

Os Massive Open Online Courses são em síntese, uma agregação do conceito de EaD (Educação a Distância) através de um AVEA (Ambiente Virtual de Ensino e Aprendizagem), oferecendo cursos abertos (sem restrições para participação ou pré-requisitos, muitas vezes gratuitos), para um grande ou ilimitado número de participantes (massivos). O acrônimo foi cunhado por Dave Cormieri, em referência ao curso organizado no ano de 2008, no qual George Siemens e Stephen Downes ministraram na Universidade de Manitoba (Canadá) o que teria sido o primeiro MOOC, intitulado "Connectivism and Connective Knowledge", CCK08, com mais de 2.300 inscritos.

Nos ideais destes pesquisadores, a visão de MOOC compreende uma plataforma gratuita, organizada para atender um número massivo de pessoas, de modo que elas pudessem se reunir e discutir sobre determinados temas ou conhecimentos de forma colaborativa, com participação e envolvimento direto dos alunos no processo de aprendizagem, de forma que o conhecimento construa-se com base na postura ativa do estudante, sendo o professor um curador de conteúdos. Estas características derivam ideologicamente do conectivismo.

Em 2011, professores de engenharia da Universidade de Stanford ofereceram três cursos na área de ciências da computação já definidos como MOOC. O curso intitulado "Introdução à Inteligência Artificial" foi oferecido de forma gratuita para estudantes do mundo todo (Santos, 2014). O resultado foi a participação de 160 mil estudantes de mais de 190 diferentes países. Esse parece ter sido o marco de uma mudança na oferta de cursos online ou ensino a distância, iniciando a formação de consórcios para a criação das grandes plataformas agregadoras MOOC em expansão até a atualidade, como Coursera, MiríadaX ${ }^{\mathrm{ii}}$, Udacity, edX e Veduca ${ }^{\text {iii }}$.

Para Cisel e Bruillard (2012) não há um consenso ao conceituar MOOC. A despeito das características comuns como serem online, abertos e massivos, houve mudanças significativas nos MOOC após o surgimento das grandes plataformas americanas ao longo de 2012. Já o primeiro MOOC, de Siemens \& Downes, e que dá origem ao termo, era uma resultante da teoria conectivista.

Nos últimos anos, observa-se a oferta exponencial de MOOC por parte de instituições de ensino seculares. O website educacional Class Central ${ }^{\text {iv }}$, especializado na catalogação de cursos neste formato e geração de estatísticas, publicou no ano de 2016 relatório apontando que em 2015 as principais plataformas agregadoras já contavam com mais de 4.200 cursos ofertados por mais de 500 instituições de ensino, num total de 35 milhões de estudantes em todo mundo.

Isto resultou em consideráveis esforços de pesquisa na América do Norte e Europa sobre os potenciais deste formato, chamando a atenção de grandes veículos de mídia como o jornal The New York Times que em 2012 publicou reportagem intitulada "Come the Revolution" (Friedman, 2012) sentenciando 2013 como o ano dos MOOC, o que se confirmou em grande parte desde o referido ano até os dias atuais. Para Daniel (2012), MOOC representou a palavra da moda na área educacional em 2012.

\subsection{Conceitos relevantes e encadeamento significativo para esta pesquisa}

Buscando subsídios para estabelecer como observar a oferta de cursos online em plataformas MOOC, a revisão bibliográfica aponta para a atenção às seguintes referências em um cenário de educação online de empreendedorismo orientado para sustentabilidade em plataformas MOOC. 
Tabela 1. Tópicos, referências e autores selecionados

\begin{tabular}{|l|l|l|}
\hline \multicolumn{1}{|c|}{ Tópico } & \multicolumn{1}{|c|}{ Referência } & \multicolumn{1}{|c|}{ Autores } \\
\hline Empreendedorismo & $\begin{array}{l}\text { Empreender é um processo de construção do futuro; } \\
\text { reconhecer uma oportunidade e o seu valor; e está } \\
\text { intimamente ligado à inovação à serviço do crescimento. }\end{array}$ & $\begin{array}{l}\text { Dolabella (2003), } \\
\text { Venkataraman } \\
(1997), \text { Santiago } \\
(2009)\end{array}$ \\
\hline Sustentabilidade & $\begin{array}{l}\text { Interesse coletivo visando gestão organizacional através de } \\
\text { políticas e práticas mais sustentáveis; reflexão em torno de } \\
\text { desenvolvimento e progresso da sociedade com a preservação } \\
\text { ambiental; tripé denominado Triple Bottom Line, abordagem } \\
\text { desenvolvida inicialmente por Elkington em 1994 com o } \\
\text { entendimento em três P's: people, profit e planet. }\end{array}$ & $\begin{array}{l}\text { Nidomolu, Prahalad } \\
\text { e Rangaswashi } \\
\text { (2009), Jacobi } \\
\text { (2003), Yamamoto, } \\
\text { (2016) }\end{array}$ \\
\hline $\begin{array}{l}\text { Educação de } \\
\text { Empreendedorismo } \\
\text { orientado para } \\
\text { Sustentabilidade }\end{array}$ & $\begin{array}{l}\text { Ideia inicial de educação empresarial como domínio } \\
\text { pedagógico predominante com novo olhar para oportunidades } \\
\text { sustentáveis; propostas emergentes sinalizam necessidade para } \\
\text { educação empreendedora guiada para sustentabilidade. }\end{array}$ & $\begin{array}{l}\text { Wyness e Klapper } \\
\text { Bossle (2015), Hermann e }\end{array}$ \\
\hline $\begin{array}{l}\text { Massive Open } \\
\text { Online Course } \\
\text { (MOOC) }\end{array}$ & $\begin{array}{l}\text { A possibilidade de reunir grandes grupos de estudantes em um } \\
\text { Ambiente Virtual de Ensino e Aprendizagem (AVEA) } \\
\text { adequado à este fim, bem como de expandir a interação das } \\
\text { instituições de ensino com as comunidades onde atuam, } \\
\text { abrindo as portas através de uma plataforma virtual, } \\
\text { estendendo os resultados das áreas de pesquisa e ensino para } \\
\text { as comunidades onde atuam, são elementos que configuram } \\
\text { uma relação próxima com as propostas subjacentes aos termos } \\
\text { "massive" e "open". }\end{array}$ & $\begin{array}{l}\text { Downes (2012), } \\
\text { Sattar (2013), }\end{array}$ \\
\hline
\end{tabular}

Fonte: Elaboração dos autores.

\subsection{Trabalhos relacionados}

A alternativa do modelo MOOC para ensino e aprendizagem de diferentes temas vem sendo estudada em diferentes trabalhos.

A pesquisa de Zanini (2016) faz um apanhado histórico da educação a distância até chegar às plataformas MOOC. $\mathrm{O}$ foco deste estudo é demonstrar as possibilidades de conectar pessoas dispostas a trocar experiências para aprender sobre determinado tema explorando as possibilidades das TICs. É realizado relato de parceria, oferta e avaliação, de curso oferecido pela Universidade de São Paulo (USP) na plataforma Coursera. A análise particular na área de de Ciências Biológicas se restringe a breves considerações a respeito da lista de cursos nesta área na mesma plataforma.

O trabalho de Brites e Rocha (2017) faz análise de cursos da área da saúde a partir de catálogo independente, e por vezes incompleto, para avaliar a oferta de cursos nesta área. Entre as principais plataformas globais os cursos encontrados eram em sua grande maioria $(81,35 \%)$ ofertados no idioma inglês, o que segundo os autores, reflete o patamar de outros estudos. Das considerações finais, extrai-se que a pequena ocorrência de cursos na área da saúde pode ter razões diversas, entre elas, restrições ao compartilhamento aberto de informação por motivações comerciais e éticas neste segmento profissional.

Desenvolvendo um trabalho baseado em pesquisa bibliográfica e estudo de caso múltiplo, Souza e Cypriano (2016), apresentaram características do conectivismo como 
fundamentação para aprendizagem em plataforma MOOC, assim como a importância da concepção de Recursos Educacionais Abertos (REA) num contexto de educação aberta. Esse embasamento guiou a avaliação, pelos pesquisadores, de cursos sobre astronomia nas plataformas Khan Academy, Coursera, Udacity, EdX e Inversity. Utilizando critérios selecionados segundo preceitos do conectivismo, características dos REAs e funcionalidades de interação e usabilidade das plataformas, estabeleceram um ranking para os players MOOC.

Neste último relato, considerou-se que, ao menos nas plataformas observadas, com base no curso de astronomia selecionado, o ensino percebido de fato se mostrou menos conectivista e menos aberto do que o modelo MOOC poderia sugerir, indicando que o discurso não corresponde à prática. Disto, surge no trabalho, uma proposta de modelo MOOC, para cursos mais conectivistas e mais abertos. $\mathrm{O}$ ensino de astronomia, segundo os autores, pode crescer explorando também as plataformas MOOC assim como observado em outras áreas do conhecimento.

No transcorrer deste artigo sobre os temas de empreendedorismo e sustentabilidade em plataformas MOOC, serão exploradas as principais plataformas, obtendo-se informações diretamente nas páginas dos cursos, para observar a relação do temas empreendedorismo e sustentabilidade e outros aspectos tidos como importantes para relevância destes cursos em sua área de conhecimento.

\section{Método da pesquisa}

A pesquisa desenvolvida neste trabalho baseia-se na observação de casos múltiplos e tem por objetivo analisar a oferta de cursos online em plataformas MOOC que contemplem as temáticas empreendedorismo e sustentabilidade. Primeiramente, buscou-se compilar a conceituação dos temas foco do estudo: empreendedorismo e sustentabilidade, por meio de uma pesquisa bibliográfica em bases científicas e em livros e teses pertinentes aos temas em questão. Este recurso foi utilizado ainda na busca de referências para o processo de ensino e de aprendizagem das temáticas citadas, apresentando ainda preceitos básicos do formato. Outra etapa central correspondeu à exploração da oferta de cursos online que relacionam empreendedorismo e sustentabilidade, buscando conhecer as principais plataformas, a disponibilidade de cursos relacionados aos temas, o formato dos mesmos, conteúdos, desenvolvidos e aspectos pedagógicos de tal oferta. A escolha das plataformas fonte da pesquisa deu-se em virtude da sua representatividade (quantidade de usuários).

A partir da revisão da literatura, são selecionadas referências para educação de empreendedorismo e sustentabilidade, as quais passam a ser critérios de observação em cursos massivos nas diferentes plataformas MOOC analisadas.

O trabalho avança explorando análises quantitativa quanto a ocorrência de cursos nas temáticas foco e análises qualitativas observando a consistência dos cursos diante da conceituação de educação de empreendedorismo e sustentabilidade.

\subsection{Revisão da literatura e pesquisa no catálogo de MOOC}

Para além de mera transcrição de ideias em livros, anais de congressos, publicações científicas em periódicos, a revisão bibliográfica é guiada pela finalidade de obter referências para o processo de ensino online de empreendedorismo articulado com sustentabilidade. Quanto a pesquisa bibliográfica, Doxsey e De Riz nos dão algumas orientações: 


\begin{abstract}
A pesquisa ou levantamento bibliográfico é um importante estágio na elaboração do quadro inicial. Se o pesquisador utiliza teorias e conceitos para estudar fenômenos, a leitura é um hábito que deve ser cultivado. Pela leitura, o pesquisador fica conhecendo o que outros pesquisadores e autores disseram a respeito do fenômeno que pretende estudar (Doxsey \& De Riz, 2003, p. 35).
\end{abstract}

No contexto deste estudo, o levantamento bibliográfico resulta na seleção de um modelo de referência que guia a verificação das informações de oferta de cursos online em diferentes plataformas MOOC.

Optou-se pela adoção de estudo de casos múltiplos, pois, serão verificados parâmetros de referência em diferentes plataformas, observando a aproximação com o modelo de referência. As plataformas MOOC selecionadas pelos autores para o estudo, a saber, Coursera, edX e FutureLearn caracterizam cada uma um estudo de caso (Yin, 2013).

\title{
3.2. Fontes de pesquisa e análise dos cursos online
}

A verificação da situação de oferta de cursos MOOC foi realizada utilizando os mecanismos de pesquisa das próprias plataformas, usando os temas (palavras) empreendedorismo e sustentabilidade em inglês. Foram coletadas as informações disponíveis sobre os cursos nas diferentes plataformas compilando uma base de dados. O período de realização da coleta de dados foi outubro de 2018.

Serviços de indexação e compilação de informações sobre cursos online em plataformas, como MOOC List ${ }^{\mathrm{v}}$, caracterizam fontes de dados secundárias e foram preteridas em nome do acesso direto a partir da fonte primária. O trabalho de Brites e Rocha (2017) é exemplo de utilização do serviço MOOC List.

\subsection{Discurso da educação de empreendedorismo e sustentabilidade e a prática na oferta}

Os dados coletados sobre a situação de oferta de cursos online massivos serão analisados de duas formas. Busca-se saber se nas plataformas MOOC existem atualmente cursos com a articulação das temáticas de interesse e se a forma de oferta destes cursos é em algum nível compatível com o modelo de referência para cursos nestes temas. Neste ponto, cabe destacar, que o objetivo não é verificar se os cursos em análise atendem ao modelo, mas, se nas práticas de oferta nas diferentes plataformas, se estão presentes elementos do modelo de referência.

\subsection{Limites metodológicos}

A seleção de um modelo de referência para ensino online de empreendedorismo e sustentabilidade a partir do levantamento bibliográfico não tem a pretensão de conceber parâmetros definitivos para curso online em plataformas MOOC, constituindo, ao contrário, apenas referência inicial aplicável para os objetivos deste estudo.

As diferentes plataformas são independentes e são, de fato, concorrentes, disputando estudantes para seus cursos. A divulgação dos cursos nas plataformas é efetivada por catálogos com informações abertas limitadas, não padronizadas, obtidas manualmente, sobre os diferentes cursos.

O retrato temporal obtido na coleta de dados exige repetição da pesquisa para permitir observação de qualquer mudança, movimento ou tendência ao longo do tempo. 


\section{Apresentação dos resultados principais}

A revisão bibliográfica viabilizou a seleção de um modelo de referência capaz de guiar a verificação da situação de oferta de cursos online.

\subsection{Modelo de referência}

O modelo selecionado é tão somente referência inicial para viabilizar a verificação de práticas de oferta de cursos online. Sendo assim, o Modelo de Referência (MR) compreende quatro tópicos principais (A, B, C e D) assim organizados (Hermann \& Bossle, 2018):

- Colaboração externa (MR/A)

- Foco educacional (MR/B)

- Instituições de educação (MR/B1)

- Contexto educativo (MR/B2)

- educação para a sustentabilidade - aprendizagem ao longo da vida ou educação não formal

- educação para o empreendedorismo - desenvolvimento institucional, saúde pública ou universidade empreendedora

- Público-alvo (MR/B3)

- Abordagens de ensino e de aprendizagem (MR/C)

- Metodologias ativas (MR/C1)

- Orientadas para o mundo real $(\mathrm{MR} / \mathrm{C} 2)$

- Temas sustentabilidade e empreendedorismo centrais nos cursos (MR/D)

A proposta de verificar a situação de oferta de cursos online nas temáticas de empreendedorismo e sustentabilidade a partir do modelo de referência não é realizada em termos rígidos de "atende ou não atende", mas em uma perspectiva aberta, de como poderia ser a oferta de cursos online.

\subsection{Situação de oferta dos cursos online}

Entre 2016 e 2017 foi observado crescimento de $38 \%$ no número de cursos ofertados em plataformas MOOC segundo relatório anual do site especializado Class Central ${ }^{\mathrm{vi}}$. O mesmo relatório também aponta quais são as principais plataformas ao redor do mundo. Estudos nesta área demonstram que a oferta de cursos ocorre em sua grande maioria no idioma Inglês para diferentes áreas do conhecimento. Este dado estabelece como critério inicial para o presente trabalho a seleção de cursos nas cinco maiores plataformas considerando apenas o idioma Inglês.

Tabela 2. Maiores plataformas MOOC e representatividade dos temas

\begin{tabular}{|l|c|l|c|c|c|}
\hline Plataforma & $\begin{array}{c}\text { Usuários } \\
\text { (milhões) }\end{array}$ & Elegibilidade para o estudo & $\begin{array}{c}\text { Total } \\
\text { Cursos }\end{array}$ & $\begin{array}{c}\text { Tópicos } \\
\text { Entrepreneur* } \\
\text { Sustainab* }\end{array}$ & $\%$ \\
\hline Coursera & 30,0 & Possibilita busca de cursos em inglês e & 2.448 & 238 & 9,7 \\
\hline
\end{tabular}




\begin{tabular}{|l|c|l|c|c|c|}
\hline edX & 14,0 & $\begin{array}{l}\text { acesso a informações } \\
\text { acesso a informações }\end{array}$ & 332 & 9,6 \\
\hline XuetangX & 9,3 & $\begin{array}{l}\text { Possibilita busca de cursos e acesso a } \\
\text { informações, entretanto conteúdo é } \\
\text { essencialmente direcionado ao público } \\
\text { Chinês }\end{array}$ & $-\mathrm{x}-$ & $-\mathrm{x}$ - & -x- \\
\hline Udacity & 8,0 & $\begin{array}{l}\text { Possibilita busca de cursos em inglês e } \\
\text { acesso a informaçôes, entretanto conteúdo } \\
\text { é essencialmente focado ao ensino e } \\
\text { aprendizado de Tecnologias da Informação } \\
\text { e Comunicação - TICs }\end{array}$ & $-\mathrm{x}-$ & $-\mathrm{x}-$ & $-\mathrm{x}$ - \\
\hline FutureLearn & 7,1 & $\begin{array}{l}\text { Possibilita busca de cursos em inglês e } \\
\text { acesso a informações }\end{array}$ & 826 & 111 & 13,4 \\
\hline TOTAL & $\mathbf{6 8 , 4}$ & & & & \\
\hline
\end{tabular}

Fonte: Elaboração dos autores.

Logo, a partir do ranking das maiores plataformas (em números de usuário), foram selecionados para esta pesquisa aquelas que possibilitam busca e coleta de informações sobre os cursos que contemplem expressões compatíveis com padrões de busca Entrepreneur* e Sustainab* e que sejam ofertados em inglês. Assim, foram selecionadas as plataformas Coursera, edX e FutureLearn para refinamento dos parâmetros de busca e compilação da base de dados de cursos neste universo.

$\mathrm{Na}$ delimitação da amostra, a busca por cursos online nos catálogos das plataformas MOOC foi realizada utilizando palavras-chaves específicas, individualmente e de forma combinada para abranger as seguintes combinações:

1. Entrepreneur

2. Entrepreneurship

3. Sustainable

4. Sustainability

5. Entrepreneur + Sustainable

6. Entrepreneur + Sustainability

7. Entrepreneurship + Sustainable

8. Entrepreneurship + Sustainability

A Tabela 3 demonstra os resultados, em termos de cursos encontrados, para a busca segundo as combinações de palavras-chave acima enumeradas.

Tabela 3. Cursos online em plataformas MOOC segundo busca por palavras-chave

\begin{tabular}{|c|c|c|c|c|c|c|c|c|c|c|c|c|c|c|c|c|c|}
\hline $\begin{array}{c}\text { PALAVRAS- } \\
\text { CHAVE }\end{array}$ & $\mathbf{T}$ & $\mathbf{1}$ & $\mathbf{\%}$ & $\mathbf{2}$ & $\mathbf{\%}$ & $\mathbf{3}$ & $\mathbf{\%}$ & $\mathbf{4}$ & $\mathbf{\%}$ & $\mathbf{5}$ & $\mathbf{\%}$ & $\mathbf{6}$ & $\mathbf{\%}$ & $\mathbf{7}$ & $\mathbf{\%}$ & $\mathbf{8}$ & $\mathbf{\%}$ \\
\hline Coursera & 2448 & 70 & 2,9 & 31 & 1,3 & 168 & 6,9 & 168 & 6,9 & $\mathbf{1 3}$ & $\mathbf{0 , 5}$ & 13 & 0,5 & 6 & 0,2 & 6 & 0,2 \\
\hline edX $^{\text {vii }}$ & 3456 & 168 & 4,9 & 140 & 4,1 & 164 & 4,7 & 112 & 3,2 & $\mathbf{2 2}$ & $\mathbf{0 , 6}$ & 13 & 0,4 & 18 & 0,5 & 11 & 0,3 \\
\hline
\end{tabular}




\begin{tabular}{|l|l|l|l|l|l|l|l|l|l|l|l|l|l|l|l|l|l|}
\hline FutureLearn $^{\text {viii }}$ & 826 & 17 & 2,1 & 46 & 5,6 & 65 & 7,9 & 65 & 7,9 & $\mathbf{4}$ & $\mathbf{0 , 5}$ & 4 &, 05 & 6 & 0,7 & 6 & 0,7 \\
\hline
\end{tabular}

Fonte: Elaboração dos autores ( $\mathrm{T}=$ Total de cursos na plataforma).

Dos dados da Tabela 3 observa-se que individualmente, os termos "Entrepreneur" e "Entrepreneurship" alcançam entre 1,3\% e 5,6\% dos cursos nas diferentes plataformas. Por sua vez, os termos "Sustainable" e "Sustainability" variam entre 3,2\% e 7,9\% dos cursos em relação ao total de cursos disponíveis.

Para a análise, a combinação de palavras "Entrepreneur + Sustainable" foi selecionada para busca por cursos, pois em duas das três plataformas, resulta em mais ocorrências de cursos.

\subsection{Aproximação do modelo de referência com a situação de oferta de cursos em plataformas MOOC}

A verificação da situação de oferta de cursos online em plataformas MOOC corresponde a observação de como ocorre a articulação das temáticas empreendedorismo e sustentabilidade em ferramenta tecnológica para ensino e aprendizagem. Desta forma, para confrontar determinado modelo com diferentes práticas, no âmbito desta pesquisa, é preciso considerar as seguintes observações para cada parâmetro do modelo.

\section{MODELO DE REFERÊNCIA}

Do modelo de referência destacam-se a seguir os pontos que guiaram a observação dos cursos nas plataformas.

\section{MR/A - Colaboração externa}

As principais plataformas MOOC do mercado correspondem a empresas de tecnologia que disponibilizam ambientes virtuais de aprendizagem para operacionalizar cursos online por parceiros credenciados a exemplo do relatado em Zanini (2016). Em sua maioria, os parceiros dos players MOOCs são as universidades e instituições de ensino e pesquisa ao redor do mundo.

A proposição e ofertas de cursos pode compreender articulação de diferentes atores para lançamento de novas e variadas opções de formação.

Neste contexto, entende-se que "Colaboração externa", seja viável considerando o contínuo crescimento na oferta de cursos abrangendo universidades e outras organizações. Isto pode ser observado no relatório anual de $2017^{\text {ix }}$ do site especializado Class Central.

Mesmo que o crescimento dos usuários tenha ficado bem estável no ano passado, novos cursos continuaram a ser criados e lançados de forma mais agressiva do que nunca. Até à data, mais de 800 universidades em todo o mundo lançaram pelo menos um MOOC. Os provedores do MOOC também estão fazendo parcerias com empresas (principalmente tecnologia) para lançar cursos. O número total de MOOCs anunciados é de 9.400 no ano passado, em comparação a 6.850. O número de MOOCs totais disponíveis para inscrição em qualquer momento também subiu devido a ajustes na política de agendamento por provedores MOOC (Class Central. Online. Tradução do original).

A cooperação de diferentes atores no desenvolvimento de cursos pode ser observada embora em pequena quantidade. Um exemplo é o curso "The Biology of Water and Health - 
Sustainable Interventions ${ }^{\mathrm{x}}$ " oferecido em parceria entre a The Open Education Consortium e a Tufts University (Massachusetts/US) através da plataforma edX.

A cooperação de diferentes atores pode promover cursos direcionados para demandas formativas específicas. No contexto de modelo de inovação Triple Helix, por exemplo, a articulação de Universidade, Indústria e Governo em determinado arranjo produtivo local pode explorar o potencial das plataformas MOOC para capacitação em empreendedorismo e inovação para geração de trabalho e renda levando qualificação às pessoas a qualquer hora e local.

\section{MR/B - Foco educacional}

Em relação ao foco educacional, o propósito desta pesquisa é intrinsecamente relacionado com a finalidade educacional da articulação dos temas empreendedorismo e sustentabilidade. O lançamento de novos cursos é promovido por plataformas MOOC em estreito relacionamento com universidades e instituições de ensino e pesquisa (MR/B1) e outras organizações e empresas ligadas ao segmento de serviços em educação e/ou tecnologia. Considera-se que variadas articulações entre diferentes instituições são viáveis para promoção contínua de novas opções para os catálogos de cursos.

\section{MR/B2 - Contexto educativo}

A coleta de dados ficou restrita a cursos de qualificação de curta duração ou programas de especialização que são formados em sua maioria por um conjunto de três a cinco cursos.

Seja através de cursos ou através de programas, observa-se na Figura 3, que cursos selecionados pela palavra chave "entrepreneur" estão ligados primordialmente às áreas de "Business" e "Business \& Management" sendo razoável relacionar tais cursos a perspectiva de formação técnica, qualificação complementar à formação do ensino superior.

Por outro lado, os cursos selecionados pela palavra chave "sustainable", embora também vinculados às áreas de "Business" e "Business \& Management", tem significativa ocorrência nas áreas de "Politics \& the Modern World", "Physical Science and Engineering", "Social Sciences" and "Environmental Studies". Tais áreas têm forte proximidade com desenvolvimento econômico, mas também com desenvolvimento e responsabilidade social. 
Figura 3. Categorias mais representativas

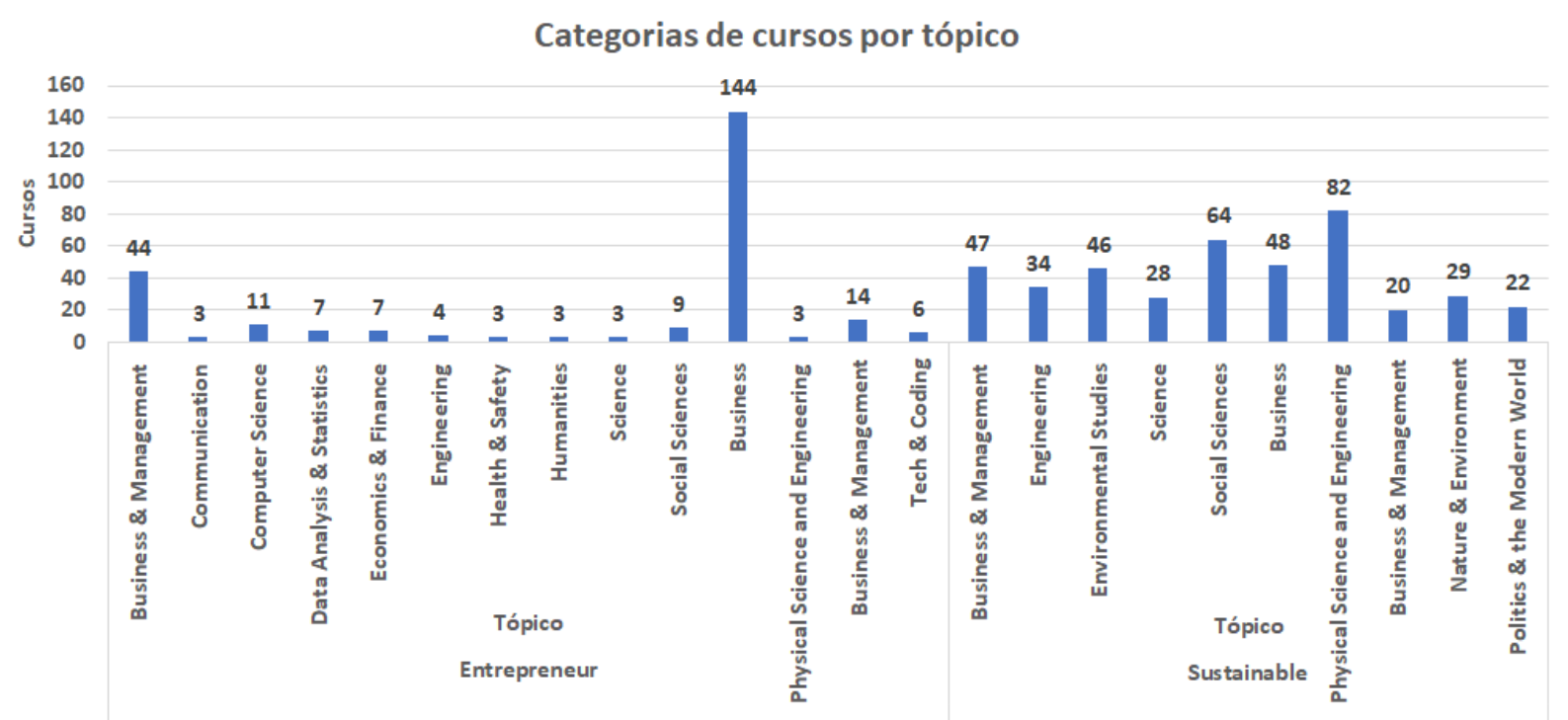

Fonte: Elaboração dos autores (categorias mantidas no original em Inglês)

\section{MR/B3 - Público alvo}

Considerando que plataformas MOOC apresentam a prerrogativa de oferecerem cursos abertos, o perfil dos estudantes de cursos online nestas plataformas pode incluir os mais diferentes conjuntos de pessoas.

Podem ser jovens buscando qualificação para ingressar no mercado de trabalho, podem ser universitários buscando complementação ou aprofundamento de técnicas ou habilidades para valorização do portfólio. Profissionais experientes buscando novos desafios ou também pessoas já mobilizadas para a atitude de aprendizagem autorregulada ao longo da vida. Tal postura habilita o usuário de $\mathrm{MOOC}$ a frequentar regularmente novos cursos nos catálogos das principais plataformas de cursos abertos massivos.

Comenta-se ainda que, as pessoas com a postura apropriada para aprendizagem autorregulada tem maior chance de completar os cursos que iniciam. Outro aspecto importante para o sucesso do processo de ensino e de aprendizagem, tanto em cursos presenciais como em cursos online, é o emprego de metodologias ativas de ensino.

\section{MR/C - Abordagens de ensino e de aprendizagem - Metodologias ativas (MR/C1) e Orientadas para o mundo real $(\mathrm{MR} / \mathrm{C} 2)$}

Embora o modelo de referência não faça distinção entre iniciativas de educação presenciais ou à distância, a concepção de MOOC subentende determinadas particularidades que estão presentes na aprendizagem a partir de um ambiente virtual de aprendizagem.

A autonomia necessária para aprendizagem na modalidade a distância é providencial para metodologias ativas. Estas contribuem para o desenvolvimento da autoconfiança, aptidão para resolver problemas do mundo real, oportuniza o trabalho em equipe, protagonismo, senso crítico e responsabilidade.

Entre os cursos online observados foram encontradas atividades que adotam metodologias ativas, especialmente desenvolvimento e apresentação de projetos abrangendo 
empreendimentos inovadores assim como elaboração de diagnósticos para aplicação de estratégias inovadoras e sustentáveis para o desenvolvimento econômico e social.

A Tabela 4 apresenta exemplos de atividades em cursos online explorando metodologias ativas na aprendizagem.

Tabela 4. Exemplos de abordagem de metodologias ativas

\begin{tabular}{|l|l|l|}
\hline Curso & Plataforma & \multicolumn{1}{c|}{ Abordagens de ensino e de aprendizagem } \\
\hline id 11 & Coursera & $\begin{array}{l}\text { Os professores desenvolveram um caso sobre uma estância de esqui hipotética que } \\
\text { oferece muitas oportunidades para desenvolver recomendações de sustentabilidade. } \\
\text { Outra opção é desenvolver uma proposta para uma mudança em sua empresa ou } \\
\text { organização. Ou os alunos podem fazer o caso e sua própria proposta. }\end{array}$ \\
\hline id 28 & Coursera & $\begin{array}{l}\text { Semana do Projeto sobre Desenvolvimento Econômico Local / Projeto Capstone } \\
\text { Junte tudo para construir uma análise da sua região. }\end{array}$ \\
\hline id 29 & Coursera & $\begin{array}{l}\text { Blast Off - Mover-se de ideias para implementação de negócios. O instrutor } \\
\text { fornece etapas tangíveis para gerar, refinar e lançar novas ideias de negócios, } \\
\text { incluindo dicas para website, logotipo, conselhos consultivos e uso de ferramentas } \\
\text { úteis, como a ferramenta popular e dinâmica de planejamento e estratégia chamada } \\
\text { Business Model Canvas. No final: lance uma oportunidade de negócio. }\end{array}$ \\
\hline
\end{tabular}

Fonte: Coursera (2018). Traduzido do original em Inglês.

Explorar aprendizagem baseada em problemas ou aprendizagem baseada em projetos oportuniza desenvolvimento de competências e a aprendizagem significativa para os estudantes e não se considera impedimento para adotar tais práticas a aprendizagem ocorrer através da Internet.

\section{MR/D - Temas principais (empreendedorismo e sustentabilidade)}

A coleta de dados realizada permitiu produzir síntese quantitativa quanto aos cursos selecionados e a representatividade e inter-relação das palavras-chave em informações cruciais dos cursos como título e programa de aprendizagem.

Tabela 5. Síntese de cursos selecionados e palavras-chaves no título e programa

\begin{tabular}{|l|c|c|}
\hline \multicolumn{1}{|c|}{ Indicador } & Ocorrências & Média \\
\hline Plataformas MOOC selecionadas & 3 & - - \\
\hline Cursos online selecionados / Média por plataforma MOOC (MPM) & 46 & 15,3 \\
\hline Número de palavras na descrição e programa do curso / Média por Curso (MPC) & $\cong 15.000$ & 326,1 \\
\hline Ocorrência do padrão entrepreneur* no título / MPC & 10 & 0,2 \\
\hline Ocorrência do padrão entrepreneur* na descrição e programa do curso / MPC & 79 & 1,1 \\
\hline Ocorrência do padrão sustainab* no título / MPC & 13 & 0,3 \\
\hline Ocorrência do padrão sustainab* na descrição e programa do curso / MPC & 64 & 1,4 \\
\hline
\end{tabular}




\begin{tabular}{|l|c|c|}
\hline \multicolumn{1}{|c|}{ Indicador } & Ocorrências & Média \\
\hline Cursos com ocorrência dos padrões entrepreneur* e sustainab* no título & 0 & $-\mathrm{x}-$ \\
\hline $\begin{array}{l}\text { Cursos com mais de uma ocorrência dos padrões entrepreneur* e sustainab* na } \\
\text { descrição e programa do curso }\end{array}$ & $5^{\text {xii }}$ & $-\mathrm{x}-$ \\
\hline
\end{tabular}

Fonte: Elaboração dos autores.

Para análise da massa de texto do títulos e informação do programa de aprendizagem foi reunido todo conteúdo textual coletado de todos cursos selecionados para aplicação de mineração de texto automatizada. Tal operação buscava estabelecer a representação gráfica dos termos mais significativos desta informação.

Foi utilizada a versão online do software Sobek ${ }^{\text {xiii }}$. A partir de determinado texto, esta ferramenta produz um diagrama conciso com os principais termos e as suas relações.

Figura 4 - Diagrama de termos e relações no texto de títulos e programas de aprendizagens.

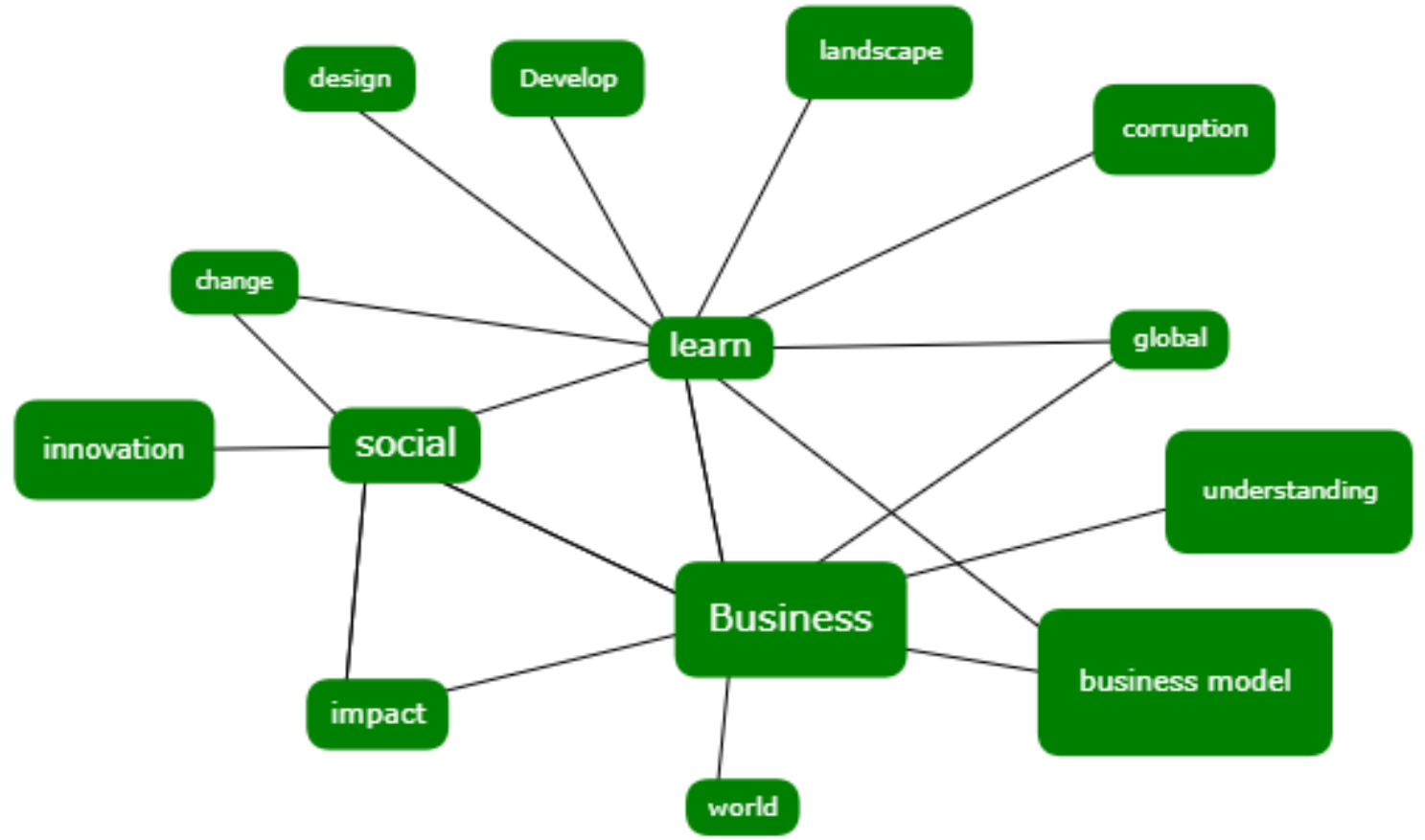

Fonte: Elaboração dos autores usando software Sobek.

Para além da centralidade do termo "learn", destaca-se a inter-relação da palavra "business" com "impact", "social", "innovation", "world" e "business model". Na proposta desta pesquisa, considera-se positivo que uma leitura possível seja a relação com conceitos centrais que passam por "educação de empreendedorismo orientado para sustentabilidade para desenvolvimento econômico e social". A ausência notável neste diagrama é palavra "sustainable" ou variações da mesma.

A não ocorrência do padrão "sustainable" também pode ser observada na pequena quantidade de cursos com múltiplas ocorrências das palavras-chaves do estudo nas informações e conteúdos do cursos. O indicador "Cursos com mais de uma ocorrência dos padrões entrepreneur* e sustainab* na descrição e programa do curso" pode ser um indicativo de que 
em cursos online existe baixo nível de articulação entre as temáticas empreendedorismo e sustentabilidade podendo indicar uma lacuna na oferta de cursos.

\section{Análise dos dados}

Enquanto a revisão bibliográfica apontou referências sobre educação de empreendedorismo orientado para sustentabilidade e sobre cursos online em plataformas MOOC, os dados coletados em três plataformas distintas, trazem informações sobre a oferta na prática de cursos nestas temáticas.

Sobre o estudo de casos múltiplos, cabe esclarecer que a análise que se faz nesta seção diz respeito sobre a informação disponível de como determinado conteúdo / temática pode ser cursado na plataforma. Entretanto, não são conhecidas de fato, as condições de participação no curso por usuários. Apenas a plataforma Coursera fornece informações sobre avaliação e comentários de usuários.

Desta forma, a análise a seguir é realizada sobre a perspectiva que tecnologicamente as plataformas têm acesso a recursos similares e podem oferecer cursos equiparáveis. A distinção entre plataformas estará restrita a funcionalidades de acesso à informação e características divulgadas dos seus cursos online. $\mathrm{O}$ que se busca neste estudo é conhecer a organização e conteúdos dos cursos para análise quanto às temáticas foco. Para comparação de funcionalidades entre plataformas existem outros trabalhos a exemplo de Souza e Cypriano (2016).

\section{Educação de empreendedorismo orientado para sustentabilidade}

Da revisão bibliográfica, pode-se extrair um consenso sobre a importância do empreendedorismo e da atenção à sustentabilidade como forma de mobilizar esforços, sejam locais ou globais, de curto, médio ou longo prazo, para o enfrentamento de complexos problemas econômicos e sociais.

As instituições de ensino e pesquisa, em especial as Universidades, precisam articular suas diferentes missões, ensino, pesquisa e inovação, de forma mais dinâmica, em sintonia com as rápidas transformações da sociedade. A capacidade de produzir conhecimento, através pesquisa e inovação, precisa ser acompanhada pela capacidade de multiplicar rapidamente o conhecimento desenvolvido em qualquer lugar.

Assim, as instituições de ensino podem articular iniciativas, em conjunto com outros atores e setores da sociedade, para contribuir para o desenvolvimento social e econômico sustentável local, regional e global.

Pertinente observar que, assim como no modelo de referência consta "Colaboração Externa", as plataformas MOOC sinalizam a possibilidade de oferta dos mais diferentes cursos de diferentes proponentes. Pode ser a oferta de uma única instituição / organização ou de um consórcio de instituições como no exemplo citado da The Open Education Consortium e a Tufts University (Massachusetts/US) através da plataforma edX. Também, o envolvimento de múltiplos atores engajados no modelo de inovação Tripla Hélice, em prol do desenvolvimento econômico e sustentável, poderia fomentar cursos online em sua área de atuação para divulgação e implantação de seu modelo de inovação. 


\section{Crescimento das plataformas MOOC como forma de potencializar a cultura da sustentabilidade}

Ao buscar informações sobre cursos online, observou-se que as três plataformas selecionadas apresentam pequenas diferenças nas opções de pesquisa e informações sobre seus cursos.

Variações que cabem destaque vêm da plataforma que não informava a classificação dos cursos no resultado das buscas, sendo necessário desenvolver um pequeno software para recuperar automaticamente as categorias na página de informações dos cursos da plataforma FutureLearn. Ainda interessante, é a disponibilidade de avaliação e comentários de usuários dos cursos na plataforma Coursera. A partir desta informação é possível ter alguma percepção da quantidade de usuários que realizaram o curso, datas de oferta, além da avaliação e comentários registrados.

Questões e problemas sociais e econômicos são muito dinâmicos. Por isso, a alternativa de contar com plataformas para oferta de cursos de qualificação em curto e médio prazo é de grande interesse para um contingente cada vez maior de profissionais. As opções formativas são variadas.

Tabela 6. Opções de cursos online das diferentes plataformas

\begin{tabular}{|c|c|c|}
\hline Coursera & edX & FutureLearn \\
\hline Formatos de cursos & Formatos de cursos & Formatos de cursos \\
\hline $\begin{array}{l}\text { - Degrees }+ \text { Certificates } \\
\text { - Programa de cursos } \\
\text { integrados } \\
\text { - Cursos }\end{array}$ & $\begin{array}{l}\text { - } \text { MicroMasters Program } \\
\text { - Professional Certificate } \\
\text { - Online Master's Degree } \\
\text { - } \text { - Xlobal Freshman Academy } \\
\text { - } \text { Cursos }\end{array}$ & $\begin{array}{ll}\text { - } & \text { Degrees (composto por Programs) } \\
\text { - } & \text { Programs (composto por Courses) } \\
\text { - } & \text { Courses }\end{array}$ \\
\hline
\end{tabular}

Fonte: Elaborado pelos autores com base nos sites das plataformas. (Nomenclatura mantida no original quando em inglês).

Cabe observar que o modelo de oferta de cursos é muito similar entre as plataformas. A construção mais elementar de qualquer oferta de formação é concretizada no curso. Os cursos, em sua grande maioria, têm entre 4 e 8 semanas de duração. A dedicação de horas de estudo por semana é variada a depender do curso. A realização do curso compreende, muitas vezes, leituras, vídeos e atividades realizadas individualmente ou em grupo através do ambiente virtual de aprendizagem incorporado na plataforma.

Esta concepção e formato de curso é muito comum e constitui a base para os programas ou trilhas de aprendizagem. Tais programas recebem designações variadas, podem compreender conteúdos e complexidades diferentes que são sinalizados como requisitos para os estudantes.

$\mathrm{Na}$ coleta de dados realizada, as informações disponíveis na plataforma Coursera, permitem observar avaliações dos usuários em cursos pertencentes a determinados programas. Tal informação possibilita inferir sobre a quantidade de alunos que completaram determinados cursos, e no contexto de programas de aprendizagem, permite considerar o número de estudantes que inicia a série de cursos e o número de estudantes que completa uma mesma série.

A Figura 5 apresenta número de avaliações em três programas distintos na plataforma Coursera. 
Figura 5. Quantidade de avaliações (alunos) de cursos organizados em programas

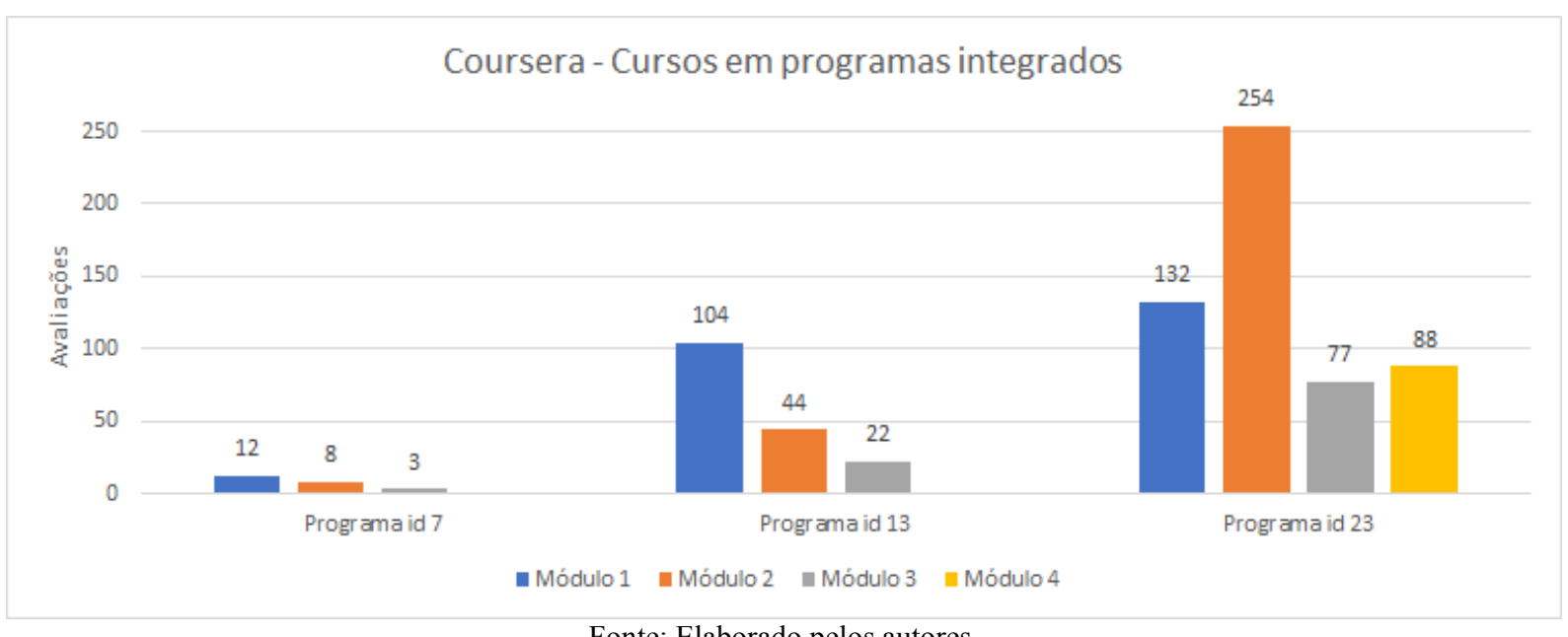

Fonte: Elaborado pelos autores.

À exceção do Programa id 23, os três programas observados na coleta de dados demonstram redução de quantidade de avaliações na sequência de cursos. Isto, eventualmente, sinaliza que os estudantes não conseguem manter o interesse e engajamento em cada módulo (curso) do programa à medida que os cursos são concluídos.

Neste cenário, para as Universidades, particularmente em países que a modalidade MOOC é menos difundida, ou onde existe demanda para temáticas específicas, certas características do modelo são especialmente conflitantes com determinadas estruturas mais rígidas de programas tradicionais de mais longo prazo de cursos superiores.

Destaque-se que além de flexível, a formação na modalidade MOOC é mais rápida se comparada, por exemplo, ao tempo de formação em curso superior. Cabe dizer que não se está aqui preterindo a formação superior, mas apenas apontando que a contribuição da Universidade na formação da sociedade pode considerar explorar cursos online na modalidade online como importante complementação formativa à valiosa formação superior oferecida.

Desta forma, mostra-se como grande oportunidade de inovação para as Universidades, em sua missão de educar, explorar o evidente crescimento dos cursos online na modalidade MOOC, multiplicando de forma dinâmica, conhecimento abrangendo os temas de empreendedorismos e sustentabilidade, através da educação tecnológica, para contribuir com o enfrentamento de importantes questões e problemas econômicos e sociais.

\section{Considerações Finais}

Diferentes pressões mobilizam esforços para o desenvolvimento econômico e sustentável de longo prazo visando atender demandas internas e externas, seja em regiões específicas, em países, em blocos econômicos ou mesmo de forma global. Uma destas demandas é a ação em prol do desenvolvimento sustentável promovido pela ONU.

A educação de empreendedorismo para sustentabilidade é importante ação neste sentido. Selecionar a articulação adequada entre ambos os temas pode depender da identificação de carência de desenvolvimento econômico e social em cada região. Instituições de ensino e 
pesquisa em todo planeta podem desenvolver ações direcionadas para as regiões onde estão inseridas e promover formação empreendedora sob medida para cada realidade.

Cursos online em plataformas MOOC podem contribuir para concepção e aplicação de formação de empreendedorismo guiado para sustentabilidade, multiplicando técnicas de empreendedorismo e atitude sustentável para enfrentamento de diferentes demandas. As Universidades e outros atores da sociedade podem atuar em conjunto para inovar também na educação empreendedora orientada para sustentabilidade direcionada para os problemas de diferentes realidades empregando abordagens pedagógicas apropriadas. Cursos online podem contribuir para resposta inicial rápida, de curto e médio prazo, para estes desafios.

Nesta pesquisa, um modelo de referência de educação de empreendedorismo para sustentabilidade foi selecionado para permitir a verificação de práticas de oferta de cursos online. $\mathrm{Na}$ análise de mineração de texto de 46 cursos online, compilando fonte textual de aproximadamente 15.000 palavras, foi produzido um diagrama de termos e suas relações. Ausência notável neste diagrama é a palavra "sustainable" ou variações da mesma. Ainda assim, considera-se positivo que uma leitura possível desta análise seja a identificação de oferta de cursos para educação de empreendedorismo, modelos de negócios e inovação ao redor do mundo que se preocupa com o impacto social decorrente.

O indicador quantitativo de "Cursos com mais de uma ocorrência dos padrões entrepreneur* e sustainab* na descrição e programa do curso" pode sinalizar que em cursos online a articulação entre as temáticas empreendedorismo e sustentabilidade é reduzida, podendo evidenciar uma carência e também oportunidade para oferta de cursos no contexto deste estudo.

A realização deste estudo apresenta uma imagem de outubro de 2018. Para verificar alguma mudança, movimento ou tendência ao longo do tempo, torna-se necessário reaplicar o estudo no futuro e analisar as variações. A partir da coleta automatizada experimental aplicada na plataforma FutureLearn, considera-se apropriado avançar na utilização de ferramentas para aumentar o nível de informação e qualificar as análises decorrentes. Outras plataformas também podem ser incluídas para se aumentar o conjunto de cursos analisados.

\section{Agradecimentos}

Os autores agradecem ao Instituto Federal do Rio Grande do Sul, a Universidade Federal do Rio de Janeiro, a Universidade Federal Fluminense e a Nord University, que no âmbito do Projeto ExPOSE - "Entrepreneurship in the post-oil transition economy Summer School", com recursos financeiros do edital UTFORSK Partnership Programme 2017-2018 do Governo Norueguês, tornaram possível o curso de verão realizado nas instalações da Universidade Federal Fluminense (Niterói e Volta Redonda - RJ, Brasil), da Universidade Federal do Rio de Janeiro (Rio de Janeiro, RJ, Brasil) e da Nord University (Bodø - Nordland, Noruega), o qual, mobilizou os autores a empreender este trabalho.

\section{Referências}

Barbieri, J. C. (2007). Gestão ambiental empresarial: conceitos, modelos e instrumentos. $2^{\text {o. }}$ ed. São Paulo: Saraiva. 
Barbieri, J. C., Vasconcelos, I. F. G., Andreassi, T., \& Vasconcelos, F. C. (2010). Inovação e sustentabilidade: novos modelos e proposições. Revista de Administração de Empresas, v. 50(, n. 2), pp. 146-154.

Blewitt, J., \& Cullingfor, C. (2004). The sustainability curriculum: the challenge for higher education. Londres: Cromwell.

Brites., L. S., \& Rocha, C. M. F. (2017). Massive Open Online Courses (MOOCS): Perfil dos cursos no campo da saúde. Revista Novas Tecnologias em Educação (RENOTE), v. 15(, n. 1). Disponível em: <http://seer.ufrgs.br/index.php/renote/article/view/75097>. Acesso em: 20/11/2018.

Carter, C. R., \& Rogers, D. S. (2008). A Framework of Sustainable Supply Chain Management: Moving Toward New Theory. International Journal of Physical Distribution and Logistics Management, 38, pp. 360-387.

Cisel, M., \& Bruillard, E. (2012). Chronique des MOOC. Sciences et Technologies de l'Information et de la Communication pour l'Éducation et la Formation, v. 19. Disponível em: <http://sticef.univ-lemans.fr/num/vol2012/13r-cisel/sticef_2012_cisel_13r.htm>. Acesso em: março de 2018.

Daniel, J. (2012). Making Sense of MOOCs: Musings in a Maze of Myth, Paradox and Possibility. Journal Of Interactive Media In Education, 3(0). Disponível em: < http://wwwjime.open.ac.uk/jime/article/view/2012-18>. Acesso em: novembro de 2018.

Dias, R. (2006). Gestão ambiental: responsabilidade social e sustentabilidade. São Paulo: Atlas.

Dolabela, F. (2003). Pedagogia empreendedora: o ensino do empreendedorismo na educação básica voltado para o desenvolvimento sustentável. São Paulo: Editora de Cultura.

Downes, S. (2012.). Connectivism and Connective Knowledge. Disponível em Stephen's Web Stephen Downes: < https://www.downes.ca/files/books/Connective_Knowledge19May2012.pdf>. Acesso em novembro de 2018.

Doxsey J. R., \& De Riz, J. (2003) Metodologia da pesquisa científica. ESAB - Escola Superior Aberta do Brasil, 2002-2003. Apostila. Disponível em: <https://cafarufrj.files.wordpress.com/2009/05/metodologia_pesquisa_cientifica.pdf >. Acesso em novembro de 2018.

Elkington, J., (1994). Towards the sustainable corporation: win-win-win business strategies for sustainable development. Calif. Manag. Rev., 36 (2), pp. 90--100. Disponível em: <http://journals.sagepub.com/doi/10.2307/41165746>. Acesso em novembro de 2018. 
Etzkowitz, H., \& Leydesdorff, L.A. (1997). Universities and the Global Knowledge Economy: A Triple Helix of University-Industry-Government Relations. London and New York:, Pinter.

Etzkowitz, H., \& Zhou, C. (2017). Hélice Tríplice: Inovação e Empreendedorismo da Universidade-Indústria-Governo. Estudos Avançados, , v. 31(n. 90), pp. 23 a 48. Disponível em: <https://dx.doi.org/10.1590/s0103-40142017.3190003>. Acesso em 21 de abril de 2019.

European-Commission. (2009). Educação para o empreendedorismo nas escolas europeias, 36. Disponível em: <https://doi.org/10.2797/039354>. Acesso em 21 de abril de 2019.

Francisco, B., \& Mariano, S. (2017). Educação empreendedora na educação básica e o homem parentético de guerreiro ramos. Cadernos Gestão e Empreendedorismo, 5(2), pp. 55-66, Mai-Ago. entrepreneurial education in basic education and the parenthetic man of guerreiro ramos.

Friedman, T. L. (2012). Come the Revolution - The New York Times. Disponível em: <http://www.nytimes.com/2012/05/16/opinion/friedman-come-therevolution.html?_r=3\&>. Acesso em: novembro de 2018.

Hermann, R. R., \& Bossle, M. B. (2018). Conceptualizing "Entrepreneurial-oriented sustainability education" through bibliometric methods. ECSB Entrepreneurship Education Conference, NORD.

Jacobi, P. (2003). Educação ambiental, cidadania e sustentabilidade. Cadernos de Pesquisa, (118), 189-206. Disponível em: <https://dx.doi.org/10.1590/S0100$15742003000100008>$. Acesso em novembro de 2018.

Jose, P. D., (2016). Sustainability Education in Indian Business Schools: A Status Review. AdMinister, (28), pp. 255-272.

Kuratko, D. F. (2005). The emergence of entrepreneurship education: development, trends, and challenges. Entrepreneurship theory and practice, 29(5), pp. 577-598.

Lourenco, F., Jones, O., \& Jayawarna, D., (2013). Promoting sustainable development: The role of entrepreneurship education. International Small Business Journal, 31(8), pp.841865.

Mattar, J. (2013). Aprendizagem em ambientes virtuais: teorias, conectivismo e MOOC. Revista Digital de Tecnologias Cognitivas (Teccogs), n. 7, pp. 20-40, jan./jun. Disponível em: $\quad<$ http://www.pucsp.br/pos/tidd/teccogs/artigos/2013/edicao_7/2aprendizagem_em_ambientes_virtuais-joao_mattar.pdf $>$. Acesso em: novembro de 2018. 
Mwasalwiba, E. S. (2010). "Eentrepreneurship education: a review of its objectives, teaching methods, and impact indicators". Education + training, 52 (1), pp.): 20-47.

Nidumolu, R., Prahalad, C. K., \& Rangaswami, M. R. (2009). Why sustainability is now the key driver of innovation. Harvard Business Review, 87(9), pp. 56-64.

Santiago, E. G. (2009). Vertentes Teóricas Sobre Empreendedorismo eEm Schumpeter, Weber eE MccLclelland: Nova Referências Para aA Sociologia dDo Trabalho.; Revista De Ciências Sociais, v. 40, pp. 87-103.

Santos, M. B. (2014). MOOCs: contexto, fundamentos teóricos e desdobramentos. In: XI Congresso Brasileiro dDe Ensino Superior aA Distância, 2014, Florianópolis. Anais. Florianópolis: UNIREDE. p. 981-992. Disponível em: <http://esud2014.nute.ufsc.br/anaisesud2014/files/pdf/128067.pdf>. Acesso em: novembro de 2018.

Siemens, G. (2004). Connectivism: A Learning Theory for the Digital Age. Disponível em < http://citeseerx.ist.psu.edu/viewdoc/summary?doi=10.1.1.87.3793>. Acesso em: novembro de 2018.

Souza, R., \& Cypriano, E. F. (2016). MOOC: uma alternativa contemporânea para o ensino de astronomia. Ciênc. educ. (Bauru), Bauru, v. 22(, n. 1), pp. 65-80, Mar. Disponível em <http://dx.doi.org/10.1590/1516-731320160010005>. Acesso em 18 de abril de 2019.

UNESCO - Organização das nações unidas para a educação, a ciência e a cultura. (1999). A Uunesco e a educação na américa latina e caribe 1987-1997. Santiago do Chile. Organização das nações unidas para a educação, a ciência e a cultura.

Valerio, A., Parton, B., \& Robb, A. (2014). Entrepreneurship education and training programs around the world: dimensions for success. World bank publications. 15.

Venkataraman, S. (1997). The distinctive domain of entrepreneurship research: An editor's perspective. In J. Katz \& R. Brockhaus (Eds.), Advances in entrepreneurship, firm emergence, and growth, vol. 3:119-138. Greenwich.

Wyness, L., J., P., \& Klapper, R. (2015). Sustainability: what the entrepreneurship educators think. Education and Training, 57(8-9), pp.834-852.

Yamamoto, P. T. (2016). Modelo conceitual de parque tecnológico proposta baseada na sustentabilidade econômica, social e ambiental. Dissertação de Mestrado, Universidade Metodista de Piracicaba, Programa de Pós-Graduação em Engenharia de Produção, da Faculdade de Engenharia Arquitetura e Urbanismo. Santa Bárbara d'Oeste-PR. 
Yin, R. K. (2013). Case Study Research: Design and Methods (Applied Social Research Methods). [s. 1.] . SAGE Publications, Inc.

Zanini, J. M. (2016). O MOOC (Massive Open Online Course) e o Ensino de Biologia. 2016. 134 f. TCC (Graduação) - Curso de Ciências Biológicas, Escola Superior de Agricultura Luiz de Queiroz, Universidade de São Paulo, Piracicaba. Disponível em: <http://www.tcc.sc.usp.br/tce/disponiveis/11/11070104/tce-10022017-090319/>. Acesso em: 18 de abril de 2019.

\footnotetext{
${ }^{\mathrm{i}} \mathrm{http}: / /$ davecormier.com/edblog/2008/10/02/the-cck08-mooc-connectivism-course-14-way/

ii https://miriadax.net/

iii https://veduca.org/

iv https://www.class-central.com/

${ }^{v}$ https://www.mooc-list.com

${ }^{v i}$ Disponível em https://www.class-central.com/report/mooc-stats-2017/

vii Do total de cursos na plataforma edX, uma parcela do catálogo consta como curso arquivado na indicação de disponibilidade.

viii A plataforma FutureLearn não informa o total de cursos disponíveis, sendo que a quantidade apurada corresponde a soma dos cursos nas diferentes categorias. Embora tal referência importe em certa incerteza os resultados das buscas palavras chave em comparação com as demais plataformas sinaliza compatibilidade quantitativa

ix $\mathrm{https}$ //www.class-central.com/report/mooc-stats-2017/

${ }^{\mathrm{x}} \mathrm{https}$ ://www.edx.org/course/biology-water-health-sustainable-oecx-ph242x

${ }^{x i} \mathrm{O}$ projeto Capstone é uma tarefa multifacetada que serve como uma experiência acadêmica e intelectual culminante para os alunos, normalmente durante o último ano do ensino médio ou do ensino médio, ou no final de um programa acadêmico ou experiência de aprendizagem (tradução dos autores). Source: The Glossary of Education Reform. https://www.edglossary.org/capstone-project/

xii Cursos id 17, 22, 33, 37 e 38.

xiii Sobek é uma ferramenta online de mineração de texto. Disponível em http://sobek.ufrgs.br/about.html
} 